\title{
FERNANDO PESSOA E A VOZ DE SHAKESPEARE
}

\author{
Dionísio Vila Maior* \\ Universidade Aberta
}

\begin{abstract}
Resumo: Procurarei refletir sobre o sentido de emulação percetível em alguns textos de Pessoa, no que às relações que com alguns outros escritores canónicos diz respeito; abordarei a relação de pensamento e de admiração que Pessoa manteve, ao longo de toda a sua vida, com Shakespeare, bem como a relação dialógica possível de deduzir nos procedimentos de criação heteronímica pessoana e na criação de personagens shakespeareana. Por essa perspetiva, procurarei concentrar-me em diversas questões: no "problema shakespeareano" (lembrando, pelas leituras de Pessoa, alguns exemplos capazes de esclarecerem um posicionamento específico do poeta português relativamente a Shakespeare); na problemática da "alteridade" - bem como na conceção pessoana de "poeta dramático", dos "graus da poesia lírica" e da "dinâmica dialógica" inerente à heteronímia de Fernando Pessoa (que nos reenviará, de imediato, para a teoria do fingimento pessoano); no problema da "figuração psicológica" inerente ao poeta dos heterónimos e ao poeta nascido em Stratford-upon-Avon; na "ansiedade da influência" (através da qual refletiremos no papel do heterónimo Alberto Caeiro).
\end{abstract}

Palavras-chave: Fernando Pessoa. Shakespeare. Dinâmica dialógica. Heterónimos. Personagens.

\section{Shakespeare, o "Grande Poeta" e o sentido de emulação}

\section{Esta obra está licenciada sob uma Creative Commons - Atribuição 4.0}

\footnotetext{
* Professor na Universidade Aberta (Portugal); Professor-Investigador da Universidade da Sorbonne (Paris IV); Membro investigador integrado do CLEPUL; Professor Convidado de diversas Universidades: Univ de São Paulo (Brasil); Univ de Santa Catarina (Brasil); Univ Autónoma de Madrid (Espanha); Univ Complutense de Madrid (Espanha); Univ degli Studi di Napoli "L'Orientale" (Itália); Univ Marie Curie Sklodowska (Polónia); Univ degli Studi di Padova (Itália). Membro da World COMMUNiCATION ASSOCiATION. Membro do Conselho Científico da Cátedra FCT Infante Dom Henrique para os Estudos Insulares e a Globalização (UAb). Coordenador da Comissão Interinstitucional do Instituto Fernando Pessoa e da Academia Lusófona Luís de Camões. Principais publicações: 100 Orpheu (em colab.), Viseu, Edições Esgotadas (2016); Do Ultimato à(s) República(s): variações literárias e culturais (em colab.), Lisboa, Esfera do Caos (2011); A revivência dos sentidos. Estudos de Literatura Portuguesa, Linda-a-Velha, Editora Hespéria (2009); Estudos Pessoanos (CDROM), Lx, Univ Aberta (CD-ROM) (2004); O Sujeito Modernista - Fernando Pessoa, Mário de Sá-Carneiro, Almada Negreiros e António Ferro: Crise e Superação do Sujeito, Lx, Univ Aberta (2003); Discursos Literatura e Fim de Século (Org.), Lx, Univ Aberta (2002); Diálogos literários luso-brasileiros (Org.), Coimbra, Pé de Página Editores (2002; Literatura em Discurso(s): Saramago, Pessoa, Cinema e Identidade, Coimbra, Pé de Página Editores (2a ed.) (2001); A Geração de 70 e a Geração de Orpheu: Portugal em Questão (em colab.), Lx, Univ Aberta (2001); Pessoa, Sá-Carneiro e Almada: Representação Estético-Ideológica, Lx, Univ Aberta (2000); Fernando Pessoa: Heteronímia e Dialogismo, Coimbra, Almedina (1994); Introdução ao Modernismo, Coimbra, Almedina (1994; 1996). E-mail: dionisiovm@gmail.com.
}

Anu. Lit., Florianópolis, v. 22, n. 1, p. 31-54, 2017. ISSNe 2175-7917 
Numa carta em inglês (escrita provavelmente em 1915), dirigida a William Bentley, Fernando Pessoa, refletindo sobre as características necessárias para um movimento literário ser «realmente grande», escreve que, se William Bentley «quiser passar os olhos por toda a literatura portuguesa do passado, encontrará um fator constante, que é a estranha falta de formas elevadas de intelecto nos seus criadores»; e exemplifica, invocando Luís de Camões:

[...] É um grande poeta épico e um razoavelmente bom poeta lírico. [...] é altamente emotivo; tem entusiasmo e sensibilidade. Mas é assinalavelmente desprovido de todas as qualidades puramente intelectuais com as quais a poesia mais elevada - e a literatura mais elevada - é construída. Não tem em si a profundidade; não tem uma profunda intuição metafísica (tal como poderia encontrar às dúzias numa página de Shakespeare). [...] Para encurtar razões, Camões, que é o mais imaginativo dos poetas portugueses antes de 1860, é, para ser brusco e franco, tão pouco inteligente como pouco imaginativo. O milagre é que, com estas desvantagens psíquicas, ele foi capaz de produzir um poema relativamente bom (PESSOA, 1996, p. 75) ${ }^{1}$.

Num outro texto (A nova Poesia Portuguesa sociologicamente considerada), publicado em 1912, Pessoa, referindo-se à nova poesia portuguesa, atribui-lhe "[...] completa nacionalidade e novidade"; depois, alerta, "para o caso de se argumentar que nenhum Shakespeare nem Vítor Hugo apareceu ainda na corrente literária portuguesa", que essa “corrente" ainda segue "no princípio do seu princípio, gradualmente, porém, tornando-se mais firme, mais nítida, mais completa"; e conclui:

[...] isto leva a crer que deve estar para muito breve o inevitável aparecimento do poeta ou poetas supremos, desta corrente, e da nossa terra, porque fatalmente o Grande Poeta, que este movimento gerará, deslocará para segundo plano a figura, até agora primacial, de Camões (PESSOA, 1986b, p. 1152-1153).

Os termos utilizados por Pessoa nestas duas reflexões, no que (também) ao universo heteronímico diz respeito, são, como se pode ver, inequívocos. Esses termos apontam para um triplo sentido: por um lado, o julgamento estético-literário que Pessoa faz de Camões, em quem não reconhece as qualidades "imaginativas", nem as «qualidades puramente intelectuais», necessárias, segundo ele, para a poesia (e a literatura) «mais elevada», considerando-o, curiosamente, «o mais imaginativo dos poetas portugueses», mas só até 1860 (Pessoa nascerá em 1888) - não sendo, nessas palavras, difícil perceber o objetivo de Pessoa.

\footnotetext{
${ }^{1}$ No original: «[...] If you will run your eye over all past Portuguese Literature, you will find one constant factor, which is the strange lack of the higher forms of intellect in its producers. Take Camões. He is a great epic poet and a fairly good lyrical one. But subject his works to an impartial analysis and try to find in him any high degree of intelligence proper. You will not succeed. He is highly emotional; he has enthusiasm and feeling. But he is signally lacking in all the purely intellectual qualities out of which the highest poetry - and the highest literature - is built. He has no depth in him; not a deep metaphysical intuition (such as you will pick up by the dozen out of a page of Shakespeare's). He has no fancy. He has no imagination, properly so-called. [...] To cut things short, Camões, who is the most imaginative of Portuguese poets before 1860 is to be blunt and frank, both unintelligent and unimaginative. The wonder is that, with these psychic drawbacks, he has been able to produce so relatively good a poem» (FP, CI: 73).
} 
No fundo, trata-se de sublinhar um juízo argumentativo onde Pessoa, reforçando uma premissa (a ausência de «qualidades intelectuais» em Camões), procura que se extraiam argumentos em favor da tese que defende. Esses argumentos encontram-se, de imediato, no segundo sentido alvejado por estas palavras: o de emulação. Percebemo-lo, quando Pessoa argumenta com a possibilidade do aparecimento do «Grande Poeta» português, que emergirá desta nova "corrente" poética, e que, forçosamente («fatalmente»), transcenderá Camões, desviando-o para «segundo plano». O sentido, porém, que, no presente contexto, mais nos interessa é aquele em que Pessoa não se isenta de legitimar a doxa pragmática, com os benefícios que o crédito do argumento de autoridade implica - argumento esse que, recordese, pode ser invocado não necessariamente quando há uma verdade empiricamente demonstrável, mas também quando a questão se centra em juízos de valor: segundo Pessoa, em Shakespeare (ao contrário de Camões), encontra-se representada uma «profunda intuição metafísica»; para além disso, note-se, Pessoa deixa com segurança antever a possibilidade de, na nova «corrente» (que ele naturalmente integra), aparecer alguém que acabe por ser comparável a Shakespeare.

\section{Pessoa e o "problema de Shakespeare"}

Estes testemunhos constituem só por si exemplos capazes de, numa primeira etapa, esclarecerem um posicionamento específico do poeta português relativamente ao poeta nascido em 1564, em Stratford-upon-Avon, não sendo alheia a tal esclarecimento uma enorme admiração de Pessoa. Desde cedo, sabemo-lo, contactou com a língua inglesa, tendo a Durban High School marcado solidamente as suas leituras dos clássicos autores anglo-saxónicos; note-se, ainda, que: aos 12 anos (em 12 de maio de 1901), escreve o seu primeiro poema em inglês ("Separated from thee treasure of my heart"); aos 15 anos, ganha o Queen Victoria Memorial Prize; entre 1903 e 1907, mostra já uma ativa produção poética sobretudo em língua inglesa assinada por uma voz outra: Alexander Search (poeta pré-heteronímico, nascido curiosamente no mesmo dia que o seu criador $)^{2}$.

Entretanto, revivamos, neste contexto, duas importantes cartas escritas por Pessoa em tempos diferentes, mas unidas, como veremos, por tópicos comuns: uma, datada de 1932, escrita a José Osório de Oliveira (seria publicada mais tarde, no suplemento literário do Diário de Lisboa, em 29 de maio de 1936); a outra, datada de 10 de Agosto de 1925, dirigida

\footnotetext{
${ }^{2}$ Curiosamente também, é a assinatura de Alexander Search que, na Biblioteca particular de Pessoa, se encontra na obra The Complete Poetical Works of Shelley (Oxford, Clarendon Press, 1904, Thomas Hutchinson [ed]), manifestando Pessoa, já por aí Pessoa, uma evidente feição alteronímica do sujeito pela qual o acontecimento estético (e o ato de leitura também se configura como tal) é irredutível ao um.
} 


\section{a Francisco Costa.}

$\mathrm{Na}$ carta dirigida a José Osório de Oliveira, Pessoa revela as importantes etapas por que passou, aquando da sua formação literária:

Em minha infância e primeira adolescência houve para mim, que vivia e era educado em terras inglesas, um livro supremo e envolvente - os "Pickwick Papers", de Dickens; ainda hoje, e por isso, o leio e releio como se não fizesse mais que lembrar. Em minha segunda adolescência dominaram meu espírito Shakespeare e Milton, assim como, acessoriamente, aqueles poetas românticos ingleses que são sombras irregulares deles; entre estes foi talvez Shelley aquele com cuja inspiração mais convivi.

No que posso chamar a minha terceira adolescência, passada aqui em Lisboa, vivi na atmosfera dos filósofos gregos e alemães, assim como na dos decadentes franceses, cuja acção me foi subitamente varrida do espírito pela ginástica sueca e pela leitura da "Dégénérescence", de Nordau (PESSOA, 1986b, p. 325).

$\mathrm{Na}$ carta dirigida a Francisco Costa, não esconde a sua posição crítica (nunca a escondeu, antes manifestando-a de forma variável) relativamente a dois dos seus principais referenciais literários:

\footnotetext{
A arte é, para mim, a expressão de um pensamento através de uma emoção, ou, em outras palavras, de uma verdade geral através de uma mentira particular. Pouco importa que sintamos o que exprimimos; basta que, tendo-o pensado, saibamos fingir bem tê-lo sentido.

Não é Shakespeare, talvez, o maior poeta de todos os tempos, pois não me parece possível antepor alguém a Homero; mas é o maior expressor que houve no mundo, o mais insincero de quantos poetas tem havido, sendo por isso mesmo que exprimia com igual relevo todos os modos de ser e de sentir, e com igual alma vivia os diversos tipos psíquicos - verdades gerais humanas - em cuja expressão se empenhou.

Para mim, pois, a arte é essencialmente dramática, e o maior artista será aquele que, na arte que professa, $[\ldots]$ mais intensa, profusa - e complexamente exprimir tudo quanto em verdade não sente [...] (PESSOA, 1986b, p. 275).
}

De notar sobretudo o significado assumido, nestas palavras, por dois elementos: por um lado, as influências literárias recebidas por Pessoa; por outro, o pressuposto estéticoliterário que norteia o pensamento de Pessoa: o fingimento (fingimento este que, diga-se desde já, não deixa nunca de constituir uma forma de sinceridade literária).

Não nos esquecendo de que, entre setembro de 1902 e dezembro de 1903, se preparava para fazer o exame de admissão à Universidade do Cabo (fazendo parte desse exame o estudo da peça Henrique V), Pessoa revela na carta dirigida a José Osório de Castro as influências e as leituras que mais o marcaram na sua «segunda adolescência», onde pontificam Shakespeare e Milton - poetas que integravam os exames de admissão e o Intermediate Examination e que aparecem bastas vezes convocados, em simultâneo, em 
diversos textos não só de Pessoa, mas também de outros eus ${ }^{3}$. Se acrescentarmos a estas informações o respeito que, durante toda a sua vida, Pessoa mostrou para com o escritor inglês, julgamos que mais facilmente se compreenderá a importância daquelas leituras. Daí as referências a Shakespeare ocorrerem de uma forma regular, mostrando Pessoa o respeito e a admiração por quem considerava um «génio» (PESSOA, 1986c, p. 40): um génio «above his age» (PESSOA, 1986c, p. 162); um «dramaturgo de génio» (PESSOA, 1986c, p. 118); um escritor cujo «lyrical genius» se manifesta no mais alto grau (PESSOA, 1986c, p. 157); alguém que, qual «iniciado esotérico», recebe, por «iniciação divina», essa marca genial (PESSOA, 1986c, p. 433) e que possui a divina «arte de interpretar os sentimentos dos outros» (PESSOA, 1986c, p. 1050); alguém «acima de todos os poetas do mundo», na «posse dos Segredos Maiores» (PESSOA, 1986c, p. 518); o mais representativo "artista" capaz de "resumir uma idade inteira e viver fora dela" (PESSOA, 1986c, p. 127); «o mais humano e universal dos poetas» (LOPES, 1990, p. 107)... Não é desconhecido, aliás, o peso axial da obra shakespeariana na vida, pensamento e produção de Pessoa; sobre isso, já alguns estudiosos se manifestaram, refletindo ou sobre a relação entre Pessoa e Shakespeare (fundamentalmente no que diz respeito à conceção de poeta dramático, à perceção da figura alteronímica, às relações dialógicas existentes). Lembro, por exemplo, os contributos de Maria da Encarnação Monteiro, Georg Rudolf Lind, Jorge de Sena, Luciana Stegagno

\footnotetext{
${ }^{3}$ No acima referido texto publicado n'A Águia, A nova Poesia Portuguesa sociologicamente considerada, Pessoa, referindo-se à história literária da Inglaterra, considera o primeiro período ( «o isabelino, que vai de 1580, aproximadamente, até a um ponto pouco mais ou menos coincidente com o fim da República») como aquele que "se impõe" na literatura inglesa, como «o maior, não só por ser mais alto o tom poético geral do período, mas também porque as suas culminâncias poéticas - Spenser, Shakespeare e Milton - põem na sombra quantos nomes ilustres os outros dois períodos apresentem» (PESSOA, 1986b, p. 1148). Na Réplica (Ao Dr. Adolfo Coelho), texto publicado na República, em 21 de Setembro de 1912, alude àquelas que ele considera serem as «duas poesias que mais se nos oferecem como brotando inesperadas e originais do seio dos seus povos»: «a poesia grega e a poesia da Renascença - preeminentemente, a da renascença inglesa», lembrando, neste contexto, a poesia que, «começando em Dante, culmina em Shakespeare e acaba em Milton»; e conclui, defendendo que «Todas as outras épocas literárias são inferiores a estas duas em originalidade» (id:: 1198). Num texto de presumivelmente 1924, na apreciação que faz dos diversos «tipos de cultura», imputa a Milton uma cultura que resulta da «erudição», a Shakespeare uma «cultura» que resulta da «experiência translata», conseguida em «tudo que via e ouvia» (PESSOA, 1986c, p. 94); juízos semelhantes são delineados num outro texto não datado, onde Pessoa diferencia a cultura de Milton («obtida por erudição deliberada e paciente») da cultura de Shakespeare, «obtida pela extraordinária universalidade do espírito, tirando resultados de tudo, aprendendo em tudo» (PESSOA, 1986c, pp. 437-438). Já no Erostratus, Pessoa sublinha a inteligência («great intelligence») de Shakespeare e o talento («great talent») de Milton (PESSOA, 1986c, pp. 40-41). De igual modo, também pela voz outra (Efbeedee Pasha, António Mora e Bernardo Soares), Pessoa não deixa de equacionar bastas vezes estes dois nomes. Numa lista que elabora para realizar recensões críticas, o outro eu Efbeedee Pasha (autor de "Stories" humorísticas) alude à importância central das obras dos «Srs. John Milton e William Shakespeare» (LOPES, 1990, p. 266). Por seu lado, António Mora, na lista elaborada dos Cadernos de reconstrução pagã, indica, no Terceiro Caderno, o título para um estudo intitulado Milton Superior a Shakespeare, a ser da autoria do próprio António Mora. Já em Bernardo Soares, em dois textos não datados (PESSOA, 1986b, p. 773 e 897), comparecem duas referências curiosas ao «dramaturgo atabalhoado William Shakespeare» e ao «mestre-escola» John Milton.
}

Anu. Lit., Florianópolis, v. 22, n. 1, p. 31-54, 2017. ISSNe 2175-7917 
Picchio, João Almeida Flor e Alexandre Severino, bem como, mais recentemente, os de Mariana Gray de Castro, Maria do Céu Lucas e Vincenzo Russo. Com efeito, Pessoa, ao longo da sua vida, lê muito sobre Shakespeare - mostrando, aliás, por diversas vezes, o desejo de traduzir algumas obras suas ${ }^{4}$. Mais: Pessoa seguia atentamente a "problema shakespeariano", que, sucintamente, incide sobre a problemática da autoria dos textos identificados como sendo de Shakespeare - dividindo-se neste contexto as posições entre os que defendem a tese ortodoxa e os que defendem a atribuição autoral a outros outro(s) autor(es) que não Shakespeare; teria sido Shakespeare o autor verdadeiro de todos os seus textos, ou teria havido o contributo autoral de Francis Bacon, ou de William Stanley (Conde de Derby), ou de Edward de Vere (Conde de Oxford)? Relativamente a este "problema", Pessoa acaba por defender a salvaguarda da "razão estético-literária" do texto, em detrimento da secundarização dessa razão promovida por algum desmando no trabalho verdadeiramente detectivesco da autoria e das questões biográfico-documentais ${ }^{6}$. E as obras lidas por Pessoa revelam isso mesmo. De um modo geral, aliás, as anotações e as observações que leva a cabo nos seus livros sobre Shakespeare concentram-se, no essencial, em três pontos: a já referida questão da autoria (manifestamente a mais visível na sua biblioteca de referências passivas), a

\footnotetext{
${ }^{4}$ Em carta dirigida a João de Castro, datada de 20 de junho de 1923, Pessoa afirma propor-se traduzir, entre outras, A Tormenta, Hamlet, O Rei Lear, Macbeth, Othelo, António e Cleópatra, O Mercador de Veneza e Sonho de uma Noite de Verão (FP, PIN: 222). Mais tarde, em carta datada de 10 de janeiro de 1930, dirigida a João Gaspar Simões, refere, de igual modo, que pretendia fazer a «tradução integral das obras (das autênticas, bem entendido) de Shakespeare» (PESSOA, 1986b, p. 283).

${ }^{5}$ Curiosamente, já em 1912, o ainda jovem Pessoa, falando sobre os seus hábitos e objetos de leitura, afirma atrevidamente: «Todos os meus livros são de consulta. Leio Shakespeare apenas em relação com o Problema de Shakespeare; o resto já o sei» (PESSOA, 1986b, p. 88) [trad. do original: «All my books are books of reference. I read Shakespeare only in relation to the «Shakespeare Problem»: the rest I know already. /I have found out that reading is a slavish sort of dreaming. If I must dream, why not my own dreams?»]

${ }^{6}$ Encontram-se, na sua biblioteca, dezenas de livros sobre Shakespeare, lidos e anotados por Pessoa. Entre outros, repare-se nos seguintes: BEECHING, H. C. (1909) - William Shakespeare player, playmaker, and poet: a reply to Mr. George Greenwood, 2nd ed., London, Smith, Elder \& Co; BORMANN, Edwin (1905) - The quintessence of the Shakespeare secret, London, A. Siegle; COLERIDGE, Samuel Taylor (1836) - Coleridge's Essays and Lectures on Shakespeare and some other old poets and dramatists, London, I. M. Dent and Sons; DEMBLON, Celestin (1913) - Lord Rutland est Shakespeare: le plus grand des mystères dévoilé Shaxper de Stratford hors cause, Paris, Paul Ferdinand; FORREST, H. T. Shakespeare (1923) - The five authors of shakespeares sonnets, London, Chapman and Dodd, Lda; GREENWOOD, G. (1909) - In re Shakespeare - Beeching v. Greenwood: rejoinder on behalf of the defendant, London, John Lane; GREENWOOD, G. G. (1908) - The Shakespeare problem restated, London, John Lane, The Bodley Head; KNIGHT, G. Wilson (1929) - Myth and miracle: an essay on the mystic symbolism of Shakespeare, London, Ed. J. Burrow and Co; LEFRANC, Abel (1918) - Sous le masque de "William Shakespeare", Paris, Payot; MASEFIELD, John (1911) - William Shakespeare: his life and works, ed. rev., London, Williams and Norgate; MATHEW, Frank (s/d) - An image of Shakespeare, London, Jonathan Cape; PELLISSIER, Georges (1914) - Shakespeare et la superstition shakespearienne, Paris, Librairie Hachette; ROBERTSON, J. M. (1930) - The genuine in Shakespeare: a conspectus, London, George Routledge and Sons, Ltd; ROBERTSON, John M. (1919) - The problem of "Hamlet", London, George Allen \& Unwin; ROBERTSON, John M. (1923) - "Hamlet" once more, London, Richard Cobden-Sanderson; ROSEAE-CRUCIS, Frates (1916) - Secret Shakespearean seals: revelations of Rosicrucian Arcana: discoveries in the Shakespeare plays, sonnets and works printed circa 1586-1740, Nottingham, J. Jenkins; SEIBEL, George (1924) - The religion of Shakespeare, London, Watts and Co.
}

Anu. Lit., Florianópolis, v. 22, n. 1, p. 31-54, 2017. ISSNe 2175-7917 
composição (e estilo) do autor inglês e a sua genialidade para a poesia dramática.

Que as reflexões sobre este último ponto são uma preocupação capital em Pessoa, prova-o, antes de mais, a acima referida carta a Francisco Costa, que nos reenvia para a questão, mais lata, do fingimento (shakespeariano e pessoano) e, irremediavelmente, para outros quesitos envolventes, marcados pelo timbre da alteridade.

\section{O princípio da alteridade e o poeta dramático}

Linhas de desenvolvimento são, então, suscitadas por esta última consideração: justamente as que incidem na tentativa de superação da consciência hegemónica do sujeito/“autor". Queremos com isto dizer que o que realmente importa vincar é o facto de o cerne do fingimento literário - e, em primeira e última instâncias, no que a Pessoa diz respeito, da heteronímia - corresponder à impossibilidade de, no caso de Pessoa, se isolar o funcionamento dos heterónimos, vozes outras, do princípio de alteridade inerente a um sujeito poético, heterónimos que assumem, em função desse princípio, uma feição autónoma em relação ao eu poético de Pessoa?

Ora, é também pelo elevado grau dessa autonomia que vinga a noção segundo a qual a heteronímia deve ser considerada como mecanismo estético-literário pluridiscursivo; ou, como diz sublinha Antonio Tabucchi, «pode dizer-se que uma das mais frequentadas problemáticas do nosso século XX, já Pessoa a sintetizara antecipadamente ao distribuir "il gioco delle parti” do seu sistema» (TABUCCHI, 1984, p. 24). Deste modo, independentemente do problema da crise do sujeito que se manifesta na literatura dos inícios do século XX, o que fundamentalmente interessa realçar nestas palavras de Tabucchi são duas sugestões que explicitam e insinuam ao mesmo tempo: em primeiro lugar, a pertinência atribuída ao verbo «distribuir», passível de chamar a atenção para a partilha que Pessoa efetua da sua posição discursiva, deixando, assim, de se assumir como um sujeito de discurso dominante; em segundo lugar, a possibilidade de equacionação dos discursos procedentes dessa partilha, de tal forma que se reconheça a cada um o carácter de veio informativo outro dotado de potencialidades autónomas dentro do «sistema» que constitui o Texto pessoano. Pessoa disse-o, como vimos, relativamente à capacidade alteronímica de Shakespeare,

\footnotetext{
${ }^{7}$ Quando nos referimos ao eu poético de Pessoa, queremos com isso sublinhar a instância discursiva particular que, a um nível estético-literário, assume a pessoa real Fernando António Nogueira Pessoa; assim se coloca em cena a questão do eu empírico e do eu textual. Evitamos, deste modo, a expressão "ele-mesmo" (tão utilizada pela exegese pessoana), de cuja utilização podem decorrer alguns riscos metodológicos. Podemos mesmo evocar, a este propósito, o testemunho de um dos mais lúcidos intérpretes de Pessoa, como é Eduardo Lourenço, para quem «a nomeação "Pessoa ele mesmo" não goza de privilégio algum nem é ortónima senão no evidente sentido empírico» (LOURENÇO, E. 1986, p. 139).
}

Anu. Lit., Florianópolis, v. 22, n. 1, p. 31-54, 2017. ISSNe 2175-7917 
quando, na carta a Francisco Costa, o compreende como "poeta dramático", não só por ser, na sua perspetiva, «o mais insincero de quantos poetas tem havido», mas também por, «com igual alma», ter "vivido" «os diversos tipos psíquicos [...] em cuja expressão se empenhou» (PESSOA, 1986b, p. 275) ${ }^{8}$. Dissera-o também em 1914 por outras palavras, num texto curiosamente dedicado a Anatole France, onde discorre sobre o diletantismo, que Pessoa entende como capacidade para "viver profundamente", «com o pensamento e com a emoção, todos os aspectos [...] da realidade ilusória» - considerando, por isso, Shakespeare como o "diletante maior", porque «viveu os tipos mais diferentes de humanidade com igual esplendor de imaginação e de inteligência» (PESSOA, 1986c, p. 173). Disse-o ainda num outro texto sem data, onde refletiu sobre a arte em geral e sobre uma capacidade de Shakespeare: imprimir ao «célebre monólogo de Hamlet sobre o suicídio e a morte» a "qualidade dramática" «da forma do pensamento assim expresso ser a natural a Hamlet» (PESSOA, 1993, p. 395-396). Mas, dentro do universo alteronímico pessoano, disse-o também o outro eu pessoano António Mora, filósofo e teórico do Neopaganismo, num texto sobre os escritores do Orpheu: refletindo sobre a complexidade e as vantagens da simplicidade da escrita, e depois de se referir ao estilo de Shakespeare e de Dante, bem como, depois, ao pecado dos órficos, que foi o terem-se exprimido «com demasiada simplicidade», afirma o direito da imaginação do «artista»: defende que «tem o direito do artista de imaginar o que não é, que outro não o é o direito que tem Shakespeare de criar um Hamlet que não existe [...]». Disse-o, de igual modo, o outro eu Raphael Baldaya (astrólogo e autor de um Tratado da Negação), quando estuda o horóscopo do «poeta dramático», exemplificando com Shakespeare (PESSOA, 1986c, p. 406-408). Disse-o, finalmente, um outro eu, Faustino Antunes (“psicólogo, autor de um Ensaio sobre a Intuição): referindo-se à «faculdade criativa do carácter (do poeta)», «construída pela imaginação e pela introspecção», sublinha que é por essa faculdade que o poeta «constrói outras pessoas a partir de si próprio» - ainda que, como considera, Falstaff seja Shakespeare «tão veramente como Pudita, Iago, Otelo, Desdémona são Shakespeare» (LOPES, 1990, p. 239).

\footnotetext{
${ }^{8}$ Registe-se que, nessa carta, ele considera Homero o "maior poeta de todos os tempos". Contudo, Pessoa variavelmente adotou esta posição relativamente a esses dois escritores, que sempre viu como os paradigmas literários; ainda que os considerando como «os dois maiores e mais criadores na vida da humanidade» (PESSOA, 1986b, p. 1183), e quase sempre classificando Homero como superior a Shakespeare, Pessoa chega, pontualmente, a interpretar o poeta inglês como "artista" superior. A esse propósito, leia-se, por exemplo, o texto António Botto e o ideal estético criador - sobretudo a passagem onde reflete sobre o "artista" (o qual, «expositor involuntário do ideal apolíneo», se encontra «entre o filósofo e o santo») (PESSOA, 1986b, p. 1259-1260) - e aquela passagem do texto A nova Poesia Portuguesa no seu aspecto psicológico, onde regista que só «na Renascença nos aparece uma figura culminante, Shakespeare, que acusa sobre Homero alguma [...] superioridade» (PESSOA, 1986b, p. 1184).
} 
Assim se ligam estas últimas palavras à conceção pessoana de «consciência individual» do poeta com capacidades dramáticas, consciência essa que (ligando-se intimamente à atividade estética de teor alteronímico) aparece caracterizada por Pessoa como aquela em que o poeta dramático fará «de si próprio como objecto o seu próprio sujeito» (PESSOA, 1986c, p. 457). Assim, ter em consideração o "poeta dramático", no sentido conferido por Pessoa, é ter em conta a sua dimensão cognoscente e organizadora, dimensão essa que acaba, no fundo, por alvejar o seu próprio desdobramento. E salientar a dimensão cognitiva relativa ao processo de autoconsciencialização significa, numa perspetiva estéticoliterária, a valorização de uma conceção dialógica do sujeito.

\section{Dos "graus da poesia lírica" à dinâmica dialógica}

No que diz respeito a este entendimento da poesia dramática, a conceção dialógica do sujeito é por demais evidente num conhecido texto de Pessoa, de, provavelmente 1930, onde reflete sobre os "graus da poesia lírica". O «primeiro grau», considera Pessoa, é «aquele em que o poeta $[\ldots]$ exprime espontânea ou irreflectidamente $[\ldots]$ [o] temperamento e [...] [as] emoções [...]»; quanto ao «segundo grau», caracteriza-o Pessoa como «aquele em que o poeta [...] não tem já a simplicidade de emoções», distinguindo-se, basicamente, os seus poemas pela "abrangência" de «assuntos diversos» ("unificados", contudo, pelo «temperamento» e pelo «estilo); sendo variado nos tipos de emoção, não o será na maneira de sentir. Pouco a pouco, caminha Pessoa para a «antecâmara» da «poesia dramática»: o «terceiro grau da poesia lírica» é «aquele em que o poeta, ainda mais intelectual, começa a despersonalizar-se» e a «sentir estados de alma que realmente não tem, simplesmente porque os compreende» (e exemplifica com Tennyson e Browning). Finalmente, os dois últimos "graus", os que realmente interessam:

O quarto grau da poesia lírica é aquele, muito mais raro, em que o poeta, mais
intelectual ainda mas igualmente imaginativo, entra em plena despersonalização.
Não só sente, mas vive, os estados de alma que não tem directamente.
Em grande número de casos, cairá na poesia dramática, propriamente dita, como fez
Shakespeare, poeta substancialmente lírico erguido a dramático pelo espantoso grau
de despersonalização que atingiu.
[...] Suponhamos, porém, que o poeta, evitando sempre a poesia dramática,
externamente tal, avança ainda um passo na escala da despersonalização. Certos
estados de alma, pensados e não sentidos, sentidos imaginativamente e por isso
vividos, tenderão a definir para ele uma pessoa fictícia que os sentisse sinceramente
[...] (PESSOA, 1986c, p. 87-88).

Apesar de longa, pensamos que a citação se justifica, uma vez que nela podemos desde logo encontrar dois pontos nucleares que nesta fase nos interessa realçar: em primeiro 
lugar, o que diz respeito ao escalonamento em direção a um posicionamento alteronímico, que, em última instância, traduzirá, num registo estético, a essência dialógica; em segundo lugar, o que aponta para a definição, ordenada, da relação entre o discurso do eu e o discurso do outro eu, problemática que inevitavelmente se liga, sobretudo no quinto «grau da poesia lírica», ao âmbito da determinação do estatuto do heterónimo. E, aqui, desde logo se pode ver como esta questão se reveste de uma enorme importância, uma vez que, conduzindo ao discurso da alteridade, ela implica - no terreno discursivo - a existência de um sujeito desdobrado ("despersonalizado"), devendo nós, por isso mesmo, privilegiar um enquadramento teórico que privilegie quatro propriedades do heterónimo: o heterónimo é um nome diferente do ortónimo, um nome próprio atribuído a um outro eu poético; depois, o heterónimo define-se como uma entidade discursiva autónoma (apresentando-se como «pessoa fictícia», mas sujeito produtor de sentidos estéticos, com características psicológicas e atributos ideológico-culturais próprios); depois ainda, o heterónimo apresenta uma escrita própria com um estilo específico e autónomo em relação ao do ortónimo; finalmente, o heterónimo é 'investido' de uma capacidade para estabelecer relações dialogais e dialógicas não só com o ortónimo, mas também com possíveis outros heterónimos.

Assinale-se a este propósito que Pessoa tinha em mente, desde cedo, juntar os poemas dos heterónimos, num livro sob o título de Ficções do Interlúdio. As palavras atrás citadas fazem parte de um desses textos, nos quais Pessoa evidencia a autonomia desses outros, dessas 'personagens' diferentes do eu. É também isso, aliás, que, de forma clara, se deduz da leitura de dois outros importantes excertos, onde Pessoa evidencia a "autonomia" estética e literária dos outros eus que cria: num deles, informa: «[...] construí dentro de mim várias personagens distintas entre si e de mim, personagens essas a que atribuí poemas que não são como eu, nos meus sentimentos e ideias, os escreveria»; e continua, logo a seguir:

Assim têm [...] [os] poemas de Caeiro, os de Ricardo Reis e os de Álvaro de Campos que ser considerados. Não há que buscar em quaisquer deles ideias ou sentimentos meus, pois muitos deles exprimem ideias que não aceito, sentimentos que nunca tive. Há simplesmente que os ler como estão, que é aliás como se deve ler (PESSOA, 1986a, p. 712).

Noutro texto, esclarece:

Umas figuras insiro em contos, ou em subtítulos de livros, e assino com o meu nome o que elas dizem; outras projecto em absoluto e não assino senão com o dizer que as fiz. Os tipos de figuras distinguem-se do seguinte modo: nas que destaco em absoluto, o mesmo estilo, me é alheio, e se a figura o pede, contrário, até, ao meu; nas figuras que subscrevo não há diferença do meu estilo próprio, senão nos pormenores inevitáveis, sem os quais elas se não distinguiriam entre si (PESSOA, 1986a, p. 709). 
E um ainda maior esforço de clarificação (ainda que limitado pela sua concisão) transparecerá na sua Tábua Bibliográfica, onde afirma que a obra «heterónima é a do autor fora da sua pessoa» (PESSOA, 1986c, p. 1424, grifo nosso) ${ }^{9}$.

Mas o que não deixa igualmente de ser interessante é a relação que, de novo, Pessoa delineia com Shakespeare, no que à composição e liberdade estilística e ideológica das «personagens» criadas diz respeito:

\begin{abstract}
Negar-me o direito de fazer isto seria o mesmo que negar a Shakespeare o direito de dar expressão à alma de Lady Macbeth, com o fundamento de que ele, poeta, nem era mulher, nem, que se saiba, histero-epiléptico, ou de lhe atribuir uma tendência alucinatória e uma ambição que não recua perante o crime. Se assim é das personagens fictícias de um drama, é igualmente lícito das personagens fictícias sem drama, pois que é lícito porque elas são fictícias e não porque estão num drama (PESSOA, 1986a, p. 712-713).
\end{abstract}

Como quer que seja, o que sobretudo nos interessa é o facto de, de um modo geral, os heterónimos pessoanos (aqueles outros eus que se ajustam ao quarto e ao quinto grau da poesia lírica delimitados por Pessoa) poderem ser avaliados como uma fuga à voz monologal e como autênticos eus literários e deverem ser assumidos em quatro vetores: no da existência mental (e, etimologicamente, existir significa 'ser diferente de', 'estar fora de') -, requisito esse que lhes reconhece, aliás, a sua existência poética no real que constitui a ficção dramática criada por Pessoa; no da escrita - enquanto concretizações discursivas e textuais; numa registo lúdico - ao qual subjaz um permanente desdobramento do $e u$ do poeta Pessoa; finalmente, numa linha de pensamento, onde seja lícito perspetivá-los não tanto como 'máscaras', mas mais como múltiplos eus de um sujeito que se desdobra.

\title{
5. Pessoa, Shakespeare e a figuração psicológica
}

Ora, é em grande parte em função da problemática aludida e da complexidade que a caracteriza que se compreende que, no plano da teoria e crítica literárias, se vislumbrem distintos e, por vezes, antagónicos rumos de leitura e de interpretação acerca da heteronímia pessoana (considerada enquanto teatralização de potencialidades subjetivas). Para todos os efeitos, mais do que perentoriamente entronizar qualquer uma das diversas interpretações,

\footnotetext{
${ }^{9}$ Note-se, no entanto, que, na conceituação pessoana, encontramos, por vezes, algumas incertezas e flutuações, quando se refere a estas "figuras fora da sua pessoa". Exemplos disso são uma carta de 19 de Janeiro de 1915, enviada a Armando Côrtes-Rodrigues (onde diz: «Mantenho [...] o meu propósito de lançar pseudonimamente [it nosso] a obra de Caeiro-Reis-Campos» (PESSOA, 1986b, p. 178), ou ainda o conjunto de designações dessas instâncias discursivas outras: «figuras», «personalidades», «autores», «personagens» (PESSOA, 1986a, p. 709, 710, 711 e 712, respetivamente), «heterónimos», «seres», «não-eus» (PESSOA, 1986b, p. 339 e 1014, respetivamente), «almas» (LOPES, 1990, p. 255), «amigos» (PESSOA, 1986b, p. 1022), «companheiros» (PESSOA, 1986b, p. 1022).
} 
importará sempre relativamente a ela praticar uma dupla leitura: a da multiplicidade (reconhecendo a especificidade dialógica e autónoma dos sujeitos poéticos da "fíç̧ão literária" pessoana) e a da univocidade (acentuando a condição de autonomia dos eus poéticos heteronímicos, resultado de um processo de desdobramento e expressão estética de atitudes literárias do sujeito poético Pessoa).

Se considerarmos, mesmo sem preocupações de inventariação exaustiva, o rumo seguido quer pela crítica pessoana, quer pelo próprio Fernando Pessoa, verificaremos que a heteronímia apresenta (entre outras, obviamente) algumas explicações que podem ser encaradas como axiais: a que aponta para tendências lúdicas de raiz infanti1 ${ }^{10}$; a explicação biografista $^{11}$; a explicação ontológica ${ }^{12}$; a que a justifica como resultado de faculdades e estéticas superiores ${ }^{13}$; a que a perspetiva como uma forma de compensação para com a crise coletiva da modernidade; a que a perfilha como uma manifestação geracional; a que a clarifica como uma resposta [mediata] ao contexto histórico-cultural ${ }^{14}$. E naturalmente que a estes enfoques explicativos da heteronímia de Pessoa se poderiam também juntar outros de igual modo importantes - baseados sobretudo nas afirmações (por vezes ambíguas, é certo) de Pessoa -, como, por exemplo, a justificação ocultista (PAZ, s/d, p. 17-18), a religiosa (CRESPO, 1988), a alquímica (QUADROS, 1989, p. 221 e 273), a que realça o processo de desdobramento como característico de um certo lusitanismo (COELHO, 1966, p. XXIXXXX; LOPES, 1977, p. 355-358), a que a avalia como resultado da descrença no poder da reflexão filosófica (GIL, 1990, p. 129), ou ainda a que a compreende como a obediência a um ideal estético (COELHO, 1966, p. XXXVI-XXXVIII).

Finalmente, e sem naturalmente pretender esgotar as diversas linhas interpretativas, evoquemos a explicação psiquiátrica. Porém, antes de avançar para essa explicação,

\footnotetext{
10 «Desde criança», escreve pessoa, «tive a tendência para criar em meu torno um mundo fictício, de me cercar de amigos e conhecidos que nunca existiram» (PESSOA, 1986b, p. 339).

${ }^{11}$ Pessoa ter-se-á apropriado de modo praticamente perfeito da língua inglesa, facto que, com a consequente identidade linguística, teria contribuído para um processo duplo de desdobramento: o de, pelo desdobramento no plano idiomático, Pessoa escrever em língua inglesa e o de, também ao nível da produção poética, se desdobrar em outros, reflexo daquele desdobramento.

${ }^{12}$ Ela decorre, em linha direta, da conceção genérica do fenómeno heteronímico como processo de que Fernando Pessoa se terá servido para procurar uma coerência interna, podendo, então, os heterónimos ser encarados como uma "alternativa" à "autodestruição" de um espírito "esquizofrenicamente dividido".

${ }^{13}$ Por esta via, encara-se Pessoa como uma personalidade distribuida e desdobrada por diversos heterónimos, nos quais projeta uma multiplicidade de atitudes, ideias, visões do mundo, resultando daí um espaço discursivoideológico de tendências polifónicas, ao alcance apenas do "poeta superior".

${ }^{14}$ É sabido como Fernando Pessoa expressou, talvez melhor do que nenhum escritor português, o dilaceramento íntimo do homem dos inícios do século XX - um homem que, diante de um mundo de dissolução do(s) discurso(s) monológico(s), feito(s) de antigos valores e crenças cristalizadas, procurou responder a essas motivações histórico-literárias de crise, representando posições ideológicas múltiplas, através de determinadas atitudes discursivas que, como tal, refletissem e/ou denunciassem essa crise civilizacional.
} 
recordemos o que Pessoa escreveu em três momentos. Num texto não datado, afirma a propósito de Shakespeare: "[...] he was automatically dulled for action, and the neurasthenic element of his character spread like a slow flood over the surface of his hysteria (PESSOA, 1986c, p. 160)"; num texto de provavelmente 1916, concorda com os psiquiatras, que, «na matéria são os competentes», sublinhando que «a pessoa de Lear denota o emprego da ideia geral de universalidade pelo instinto psicológico de Shakespeare»; e conclui: "No mesmo autor [...] encontra[-se], no dizer das mesmas autoridades, um bom número de casos análogos, como o da histero-neurastenia de Hamlet e o da histero-epilepsia de Lady Macbeth (PESSOA, 1986c, p. 117); finalmente, num fragmento textual de provavelmente 1928, dedicado a Shakespeare, desenvolve uma reflexão sobre a relação entre "genialidade" e "histeria". Reforçando a noção segundo a qual «The basis of lyrical genius is hysteria» (ideia que lembra o Dichtung und Neurose, de W. Stekel, para quem todos os poetas e artistas seriam neuróticos), distingue três tipos de histeria: a "histeria física" (encontra-a em Byron e Shelley), a "histeria mental" (presente em Victor Hugo) e a "histeria puramente intelectual", delimitada pela completa "despersonalização"; conclui, reconhecendo Shakespeare como um «hystero-neurasthenic» (PESSOA, 1986c, p. 157-158).

No quadro, portanto, de uma discursividade estético-literária muito particular, a referência, nas múltiplas reflexões sobre Shakespeare, de Pessoa a fatores de índole psicológica (e/ou que com eles mediata ou imediatamente se relaciona) assume um relevo considerável. E também por isso se reveste de valor crítico esta conexão entre "génio" e "histeria", entre "génio" e "neurastenia", entre "génio" e "histeroneurastenia", valor esse que entretanto se amplifica quando, afinal, aquela relação se estende ao próprio Pessoa.

E é o próprio Pessoa quem imprime um sentido psicológico à criação heteronímica, numa carta (datada de 10 de Junho de 1919) que escreveu (não se sabe se foi enviada) a dois psiquiatras franceses - Hector e Henry Durville:

\footnotetext{
Do ponto de vista psiquiátrico, sou um histeroneurasténico, mas felizmente, a minha neuropsicose é assaz fraca; o elemento neurasténico domina o elemento histérico, e disso resulta que não tenho sinais histéricos exteriores - nenhuma necessidade de mentira, nenhuma instabilidade mórbida nas relações com os outros, etc. Minha histeria é apenas interior, e somente minha; na minha vida comigo mesmo tenho toda a instabilidade de sentimentos e sensações, toda a oscilação de emoção e vontade que caracterizam a nevrose proteiforme. Excepto nas coisas intelectuais onde cheguei a conclusões que tenho como certas, mudo de opinião dez vezes por dia [...] (PESSOA, 1986b, p. 229).
}

Como se vê, também Pessoa, em autodiagnóstico, encara a sua própria personalidade de acordo com uma perspetiva psiquiátrica, nomeadamente no que toca à definição de si como 
«histeroneurasténico» (com predomínio para o elemento neurasténico). Virado especificamente para componentes precisos do domínio da psicologia e da psiquiatria, Pessoa acentua em especial dois aspetos da sua personalidade: a heterogeneidade e a inconstância. Deste modo, considerando-se a personalidade quer como uma "estrutura aberta", quer como uma potencialidade ativa de interação ou de comunicação com o mundo, quer como uma "estrutura" constituída funcionalmente por uma rede ativa e por potencialidades dinâmicas de relações com o mundo, quer ainda como produto de uma rede de interações com um conjunto de circunstâncias culturais e espácio-temporais em que se encontra inserida e em que age (das quais resulta uma elaboração de respostas construídas pela interação com esse mundo) ${ }^{15}$, deste modo, dizíamos, é possível retirar uma ilação: a que aponta para uma fundamentação inconstante e transitória da personalidade de Fernando Pessoa, desse traço decorrendo, de um ponto de vista estético e ontológico, uma «instabilidade de sentimentos e sensações» e a «oscilação [...] de vontade» («mudo de opinião dez vezes por dia»).

Indo ao encontro desta explicação, Pessoa, na famosa carta enviada a Adolfo Casais Monteiro a 13 de janeiro de 1935 (em que descreve o 'nascimento' dos heterónimos e o fenómeno heteronímico em si), procura também dar uma explicação de teor psiquiátrico:

Passo agora a responder à sua pergunta sobre a génese dos meus heterónimos. Vou ver se consigo responder-lhe completamente.

Começo pela parte psiquiátrica. A origem dos meus heterónimos é o fundo traço de histeria que existe em mim. Não sei se sou simplesmente histérico, se sou, mais propriamente, um histero-neurasténico. Tendo para esta segunda hipótese, porque há em mim fenómenos de abulia que a histeria, propriamente dita, não enquadra no registo dos seus sintomas (PESSOA, 1986b, p. 339) ${ }^{16}$.

É evidente a relação entre o texto das duas cartas. Mais uma vez, o Pessoa-criadordos-heterónimos acentua o carácter «neurasténico», segundo ele subjacente, antes de tudo, ao aparecimento dos heterónimos; os fenómenos histéricos ter-se-iam então mentalizado nele, manifestando-se, a um nível existencial, no silêncio e no voltar para o seu interior e, a um nível estético, pelo desdobramento em eus literários. De certo modo, esta questão, como se apresenta em Pessoa, reveste-se de uma importância particularmente significativa, atitude de que se não pode dissociar, antes de mais, uma dimensão esteticamente consequente, no que toca à relação com Shakespeare - acabando por sobressair de igual modo uma perceção sobre o fenómeno de "desdobramento" shakespeariano, sobretudo quando essa perceção se alarga a outros considerações. Num fragmento textual (com a indicação "Prefácio (aproveitar para

\footnotetext{
${ }^{15}$ Sobre este conceito de personalidade, cf. NUTTIN, J., 1982, p. 173-209.

16 Repare-se que naquela que será uma outra versão desta mesma carta, Pessoa afirma de igual modo: «Sou, psiquiatricamente considerado, o que se chama um histero-neurasténico» (LOPES, 1990, p. 378).
}

Anu. Lit., Florianópolis, v. 22, n. 1, p. 31-54, 2017. ISSNe 2175-7917 
Shakespeare)"), Pessoa autocaracteriza-se com possuindo «um temperamento feminino [...] com uma inteligência masculina [...]. É uma inversão sexual fruste»; e remata: «Somos vários desta espécie, pela história abaixo - pela história artística sobretudo. Shakespeare e Rousseau são dos exemplos, ou exemplares, mais ilustres» (PESSOA, 1966, p. 27-28); num outro texto de provavelmente 1913, afirma que, «na personalidade de Shakespeare», não podemos separar «a intuição dramática de, por ex., a inversão sexual» (PESSOA, 1986c, p. 34) ${ }^{17}$.

No entanto, podemos perguntar até que ponto são válidas estas explicações que nos aponta para a leitura do fenómeno quer da genialidade, quer, neste contexto, do desdobramento em figuras outras como decorrendo de um processo de figuração psicológica. Segundo alguns críticos, a explicação de "histeroneurastenia" não é muito viável, uma vez que o desdobramento da personalidade (nos histéricos) é, de um modo geral, um processo de curta duração e acarreta ainda a absoluta perda de consciência da personalidade originária. Ora, em Pessoa, a heteronímia prolonga-se não só por mais de vinte anos, mas igualmente de modo lúcido e consciente.

É certo que também se poderia aceitar, em parte, a explicação psiquiátrica avançada por Pessoa ${ }^{18}$; ela não é de todo incongruente, ou falsa, mas não é completa. Contudo, pensamos que o que aqui em especial interessa sublinhar é que, mais do que concebermos o desdobramento heteronímico como resultado da crise de uma personalidade, devemos equacioná-lo como o processo de um sujeito poético considerado na sua pluralidade literária tudo isto no quadro de uma conceção crítica do fenómeno literário, à qual deve presidir a solidez teórico-epistemológica. Assim pensa também Tabucchi, justamente quando, referindose à possibilidade de ler a heteronímia sob o prisma psicológico, esclarece de forma extremamente lúcida:

Não há nenhum caso clínico a descobrir na heteronímia de Pessoa, apenas uma

\footnotetext{
${ }^{17}$ Curiosamente, para além de o considerar recorrentemente um dos maiores escritores de sempre, Pessoa encontra também em Shakespeare a marca do fracasso e encara-o demasiado grande para o seu génio: «Shakespeare is the greatest failure in literature [...]» (PESSOA, 1986c, p. 164); ou ainda «Great as his tragedies are, none of them is greater than the tragedy of his own life. The Gods gave him all great gifts but one; the one they gave not was the power to use those great gifts greatly. / [...] He stands before us, melancholy, witty, at times half insane, never losing his hold on the objective world, ever knowing [158] what he wanted, dreaming ever high purposes and impossible greatnesses, and waking ever to mean ends and low triumphs. This, this was his great experience of life; for there is no great experience of life that is not, finally, the calm experience of a disillusion. / His wavering purpose; his unsettled will; his violent and fictitious emotions; his great, tormless thoughts; his intuition, the greatest that has ever been, seeing right through a thought and expressing it as if the thought itself spoke living an alien life down to its blood and flesh and speaking from it as the man himself could never have done $[\ldots]$... (PESSOA, 1986c, p. 158-159).

${ }^{18} \mathrm{O}$ próprio Pessoa enunciou-o de modo lúcido e taxativo: «Não nego, porém - favoreço, até-, a explicação psiquiátrica, mas deve compreender-se que toda a actividade superior do espírito, porque é anormal, é igualmente susceptível de interpretação psiquiátrica» (PESSOA, 1986b, p. 1024).
} 
"simples loucura", do mesmo modo que talvez seja "simples loucura" toda a literatura. Para explicar Pessoa e, talvez mesmo, para neutralizar a inquietação que ele nos transmite, falou-se de perturbações e de traumas, de carências afectivas, de complexo de Édipo, de homossexualidade recalcada. Talvez seja tudo isto e nada disto, mas não é esta a questão e não é isso que conta (TABUCCHI, 1984, p. 23-24, grifos nossos).

A questão é, assim, da ordem de uma leitura que, quer relativamente a Shakespeare, quer relativamente a Pessoa, se deve processar não em termos exclusivamente psicológicos, antes em termos fundamentalmente estético-literários, para onde decorre a consideração dialógica do ato de produção estético-literária.

\section{Da criação dos heterónimos (Pessoa) e da criação das personagens (Shakespeare)}

A partir daqui, dispomos já de algumas indicações suficientemente claras para melhor equacionar e avaliar o valor que as considerações de Pessoa adquirem na sua poesia e na dos seus heterónimos. Pessoa recorre, de facto, a Shakespeare para refletir sobre o desdobramento heteronímico: «Ler Shakespeare, ler sobre Shakespeare, cogitar sobre Shakespeare e, sobretudo, escrever sobre Shakespeare», diz-nos Mariana Gray Castro, «foi, para Pessoa, uma forma de pensar e escrever sobre si próprio. É neste sentido que podemos falar da autobiografia shakespeariana de Fernando Pessoa» (CASTRO, 2012, p. 322). Correto. E correto é dizer também que Pessoa encara Shakespeare sobretudo como poeta dramático (e não tanto como poeta lírico, ou dramaturgo), ou, ainda, que Pessoa compara a criação de heterónimos à criação de personagens pelo escritor inglês. Por essa perspetiva, poder-se-ia pensar que os heterónimos teriam a mesma natureza que as personagens shakespearianas; porém, não é bem assim.

As palavras de Finazzi-Agrò permitem-nos, a este nível, tirar uma ilação importante, concretamente quando afirma:

\footnotetext{
A recusa do seu papel de enunciante comporta [...] para Pessoa uma espécie de dialectização de informação, já não garantida [...] por um sujeito transcendental, antes confiada a um grupo de "personagens", de porta-vozes [...] (FINAZZI-AGRÒ, 1987, p. 129).
}

Encarada como entidade que, pela renúncia a uma estabilidade discursiva monológica, se nega como «transcendental», o sujeito pessoano, conceituado nestes termos, facilmente evidencia uma possibilidade: a de funcionar como espaço da pluralidade vocal, assumindo cada um dos eus em que se desdobra esse sujeito uma consciência, uma voz que dialoga com os outros eus. E, no universo poético pessoano, esta problemática reveste-se de especial interesse por nele se empreender precisamente essa dinâmica de interação. Num 
fragmento textual projetado para prefaciar as Ficções do Interlúdio, Pessoa afirma:

Há autores que escrevem dramas e novelas; e nesses dramas e nessas novelas atribuem sentimentos e ideias às figuras, que as povoam, que muitas vezes se indignam que sejam tomados por sentimentos seus, ou ideias suas. Aqui a substância é a mesma, embora a forma seja diversa (PESSOA, 1986b, p. 1020).

Repare-se que transparece nestas afirmações uma sugestão muito importante: a de que a compreensão da dinâmica heteronímica deve assentar sobre um investimento interpretativo capaz de perspetivá-la como análoga à do drama e à da novela. Neste caso, o que estaria em causa seria delimitar e conceituar os traços característicos da heteronímia, com ênfase especial na essência dramático-romanesca que os nortearia. Tudo isto sem se esquecer a importância atribuída à relação que Pessoa estabelece entre os princípios da criação (e existência) dos seus heterónimos e os das personagens dos dramas de Shakespeare ${ }^{19}$. De facto, quando sublinha, como vimos, que o poeta, no quarto grau da poesia lírica, «entra em plena despersonalização» (PESSOA, 1986c, p. 88), caindo, por isso, «na poesia dramática [...] como fez Shakespeare, poeta substancialmente lírico erguido a dramático pelo espantoso grau de despersonalização que atingiu» (PESSOA, 1986c, p. 88), Pessoa mais não faz do que estabelecer uma conexão de incidência técnico-literária entre si e o "poeta dramático" inglês. Sabe-se, porém, que esta articulação não escapou aos riscos de um mecanismo comparativo que envolve os aspetos essenciais desse procedimento literário. Com efeito, é já bem evidente, no amplo contexto da exegese pessoana, que os heterónimos, apesar de inexistentes, são seres mais verdadeiros, mais autónomos, mais credíveis do que as personagens dos dramas de Shakespeare; são personalidades assumidas, gente, sujeitos que percorrem existências poéticas paralelas à do sujeito poético Pessoa, características estas que os diferenciam quer das personagens dramáticas de Shakespeare, quer da relação que este com elas mantém. Shakespeare preocupava-se com as suas personagens até ao momento em que passavam a ter existência; depois de criadas, é cortado o "cordão umbilical" entre elas e o seu autor, ao contrário dos heterónimos de Pessoa («Les diverses "sub-personnalités” de Pessoa, par contre, ne commettront jamais le Meurtre du Père [...]» (PICCHIO, 1985, p. 31). Pessoa nunca deu por concluída a vivência (literária) dos heterónimos, colocando-os em constante diálogo entre

\footnotetext{
19 Atente-se no que a este propósito escreveu Pessoa: «Supunhamos que um supremo despersonalizado, como Shakespeare, em vez de criar o personagem de Hamlet como parte de um drama, o criava como simples personagem, sem drama. Teria escrito, por assim dizer, um drama de uma só personagem, um monólogo prolongado e analítico. Não seria legítimo ir buscar a esse personagem uma definição dos sentimentos e dos pensamentos de Shakespeare, a não ser que o personagem fosse falhado, porque o mau dramaturgo é o que se revela» (PESSOA, 1986a, p. 712). Ao mesmo problema alude Pessoa noutro lugar, quando, no rascunho de uma carta enviada a Adolfo Casais Monteiro, afirma: «Não me custa admitir que eu seja louco, mas exijo que se compreenda que não sou louco diferentemente de Shakespeare» (PESSOA, 1986b, p. 1024).
}

Anu. Lit., Florianópolis, v. 22, n. 1, p. 31-54, 2017. ISSNe 2175-7917 
si (e com o próprio ortónimo).

Que esta é uma questão cuja importância é forçoso acentuar, prova-o suficientemente a noção segundo a qual a unicidade da heteronímia de Pessoa virá não tanto da criação / produção de autores fictícios com perfis estéticos, ideológicos, culturais, próprios, mas sobretudo da "entreação" entre si, do diálogo que desenrolam entre si. Mais: uma das características do estatuto do heterónimo é, como já foi dito, a possibilidade de este dialogar não só com outros heterónimos, mas também com o sujeito que o criou. É, pois, em função da articulação dialogal entre várias vozes que, configurando um específico processo discursivo, se institui um universo dialógico determinado. Como se resolve isso na poesia dos heterónimos?

Nas Notas para a recordação do meu mestre Caeiro (PESSOA, 1986a, p. 735-740), para por exemplo, além de ver e descrever Alberto Caeiro, Campos recorda também a «primeira conversa» (PESSOA, 1986a, p. 736) que com ele tivera, a conversa em que Caeiro lhe revelara o conceito de infinito (PESSOA, 1986a, p. 737-739), ou ainda o diálogo através do qual Caeiro se lhe [não] definira («E eu perguntei de repente ao meu mestre Caeiro, “está contente consigo?". E ele respondeu: "Não: estou contente”» (PESSOA, 1986a, p. 739). Não menos importante do que estes textos são outros em que Campos se relaciona com Ricardo Reis: a polémica sobre a classificação das artes (LOPES, 1990, p. 473), ou então o «Diálogo ou controvérsia...» a propósito do conceito de poesia (PESSOA, 1986b, p. 1073-1075).

Embora pontuais, trata-se, como é evidente, de referências extremamente significativas, capazes, só por si, de clarificar as exigências de exemplificação solicitadas pela técnica de elaboração do discurso dialogal (e dialógica, note-se) entre os heterónimos. No entanto, o que nos parece ainda mais expressivo é o facto de, no amplo universo pessoano, o intercâmbio discursivo, em que cada um dos participantes funciona sucessivamente como protagonista da enunciação, não surgir limitado à interação entre Campos, Caeiro e Reis, mas também estabelecendo-se entre estes eus e o próprio eu pessoano. Nesta ordem de ideias, esta elaboração discursiva em que o eu pessoano se coloca ao mesmo nível estético e literário que os seus outros eus heteronímicos constitui um procedimento estético-literário capaz de assegurar o compromisso entre a eficácia e a preservação da especificidade dialógica, que, por vezes, se estende, inclusivamente, ao plano histórico-existencial; como diz Teresa Rita Lopes:

[...] [a] "entreação" [entre os heterónimos] não é só "intellectual" e não se limita aos confrontos de ideias que Pessoa desencadeou nas tais "discussões em família" [...]: é uma entreação existencial em que as personagens se relacionam, confrontam, influenciam como seres vivos, com destinos próprios (vejam-se os horóscopos). Não podemos, além disso, esquecer que Pessoa aparece nesse drama-em-gente como 
personagem também, ao mesmo nível dos outros [...] (LOPES, 1990, p. 186).

\section{Pessoa, Shakespeare, Caeiro e a "ansiedade da influência"}

Com o que se escreveu, cremos ter reforçado algumas possibilidades de considerar a presença shakespeariana em Pessoa, no que particularmente concerne a alguns dos contornos mais significativos que a delimitam: um desses contornos prende-se com o equacionamento sobre a despersonalização do sujeito - questão mediatamente relacionada com os procedimentos estéticos que, de uma maneira geral, conformam a procura da sua autonomia estética e o enquadramento do registo da pluralidade (dentro do contexto da afirmação polifónica dos outros eus).

É isso que Fernando Pessoa sugere, num texto de provavelmente 1930, ao envolver o heterónimo com uma moldura de características particulares, reclamando para essa figura outra uma condição autónoma, sim, mas, sobretudo, dinâmica, vital, dialógica. Por um lado, afirma que «nunca teve uma só personalidade, nem pensou nunca, nem sentiu, senão dramaticamente»; declara que, enquanto «autor humano», não concorda, «nem discorda» com o que esses outros eus escrevam, ou pensam, ou defendam; ensina que a cada outro eu heteronímico ele «deu uma índole expressiva», fazendo dele «um autor, com um livro, ou livros, com as ideias, as emoções, e a arte dos quais, ele, o autor real [...] nada tem, salvo o ter sido, no escrevê-las, o médium de figuras que ele próprio criou» (PESSOA, 1986b, p. 1019-1021).

A heteronímia pessoana deve, é certo, ser encarada como fenómeno de desdobramento do sujeito, como manifestação de alteridade literária, de fingimento estético, de insinceridade humana (tal como as personagens criadas por Shakespeare, que Pessoa considera «o mais insincero de quantos poetas tem havido» (PESSOA, 1986b, p. 275)). Isso não anula, naturalmente, o seu caráter ficcional, mas de igual modo não invalida, antes obriga, considerá-los como autênticos eus literários - em sintonia, aliás, com o argumento que Pessoa apresenta para a "realidade" das personagens shakespearianas, "realidade" sobrevalorizada pela crítica do século XIX:

\footnotetext{
Afirmar que estes homens todos diferentes, todos bem definidos, que lhe passaram pela alma incorporadamente, não existem - não pode fazê-lo o autor destes livros; porque não sabe o que é existir, qual, Hamlet ou Shakespeare, é que é mais real, ou real na verdade (PESSOA, 1986b, p. 1021).
}

Trata-se, como se vê, de um juízo muito próximo daquele que seria formulado por Jonathan Bate, quando disse, por outras palavras, que «The genius of King Lear is that it was written by a man who was totally unlike his creation» e que a chave para a «arte dramática»é 
a «Insincerity» (BATE, 1997).

Na cena VII do II Ato da comédia As You Like It, Shakespeare, pela voz de Jacques, enuncia uma tirada que se tornou paradigmática do pensamento do autor inglês: «All the world's a stage / And all the men and women merely players; / They have their exits and their entrances». Fica a noção de uma conceção particular da vida real e da escrita literária como um amplo e complexo todo capaz de desencadear relações entre um eu (o autor, o escritor, o poeta dramático, o encenador) e um outro (o espectador, o leitor, a personagem, o ator), palcos esses onde seja lícito encarar essas relações como um conjunto de formulações discursivas dialogicamente conjugadas entre si. Só assim se conseguirá equilibrar dois componentes fundamentais: o dinamismo intrínseco da representação poética (sem o qual a própria condição do discurso poético poderia ser posta em causa) e as linhas de força que orientam o processo poético - sintetizadas nos binómios eu pessoal/eu poético, eu monológico/eu dialógico, sinceridade/fingimento e mentira/verdade -, dominadas por intuitos de descentramento do sujeito.

É, de igual modo, tendo em conta a configuração em que esta problemática assenta que o ato de escrever propriamente dito acaba por assumir nas reflexões de Pessoa uma importância inegável, a que uma dinâmica de teor metaliterário não é indiferente. Dessa dimensão, encontram-se indissociavelmente ligadas, como vimos, questões relacionadas com a alteridade, o desdobramento e o dialogismo, mas, acima de tudo, a consciência e a lucidez com que Pessoa encara o ato de produção estético-literária. O que acontece é que, entretanto, quando Pessoa dimensiona esta questão, vai convocando a figura de Shakespeare, procurando talvez assim atingir dois objetivos: sustentar a sua conceção intelectualista do fazer poético e legitimar o seu fazer estético-literário, circunstância que lhe permite "obrigar" o leitor, o crítico, a avalizarem-no no mesmo plano de construtividade estético-literária que o autor inglês: «Não me custa admitir que eu seja louco», confessa na conhecida carta a Adolfo Casais Monteiro; e previne: [...] mas exijo que se compreenda que não sou louco diferentemente de Shakespeare, qualquer que seja o valor relativo dos produtos do lado são da nossa loucura» (PESSOA, 1986b, p. 1024);

E, a este propósito, como não evocar uma outra carta, essa datada de 11 de dezembro de 1931 e dirigida a João Gaspar Simões, onde Pessoa resume toda esta questão?

O ponto central da minha personalidade como artista é que sou um poeta dramático; tenho, continuamente, em tudo quanto escrevo, a exaltação íntima do poeta e a despersonalização do dramaturgo. [...] Desde que o crítico fixe [...] que sou essencialmente poeta dramático, tem a chave da minha personalidade (PESSOA, 1986b, p. 302). 
Ora, é em sintonia com esta perspetivação dialógica do «poeta dramático» que, em definitivo, se torna legítimo adivinhar (compreendendo-o, talvez, como uma transcensão de alguma "ansiedade da influência") a funcionalidade intrínseca que (também por aí) caracteriza o heterónimo Alberto Caeiro, o mestre de Pessoa e o mestre de todos os outros heterónimos. E, nesse plano, se alguma homologia existe entre o fazer poético pessoano e o fazer literário shakespeariano, ela verifica-se fundamentalmente ao nível da noção de sinceridade literária, através da qual entram, precisamente, em coincidência Shakespeare e Caeiro - esse, sim, o «mestre glorioso» (PESSOA, 1966, p. 168) de Pessoa; escreveu-o Pessoa, autorizando Álvaro de Campos (porque aí certamente que concordaria com o heterónimo). Num texto publicado no $n^{0} 3$ da revista Sudoeste, no mesmo mês e ano em que Pessoa morreu (novembro de 1935), Campos atribui essencialmente a grandeza de Shakespeare à sua dominante «sinceridade intelectual»; acaba, no entanto, por destacar o seu «mestre Caeiro» como «o único poeta inteiramente sincero do mundo» (PESSOA, 1986b, p. 1097).

Por aqui igualmente se vê como o amplo Texto heteronímico não surge apenas como fator valorizável em função de uma qualquer perspetiva que sobre ele incida; ele aparece ao mesmo tempo como sinónimo enriquecido de espaço polifónico, o qual só se concebe enquanto conjunto de planos discursivos cuja leitura é motivada pela necessidade de se respeitar as manifestações autónomas, pluridiscursivas, que neles se verifica.

E o que estas palavras inequivocamente realçam é, em conclusão, a exigência em se alargar a compreensão da presença de Shakespeare na obra de Pessoa, no que aos fundamentos dialógicos e práticas alteronímicas diz respeito. «Parece escusado», escreve Pessoa «explicar uma coisa de si tão simples e intuitivamente compreensível. Sucede, porém, que a estupidez humana é grande, e a bondade humana não é notável» (PESSOA, 1986a, p. 713).

\section{Referências}

\section{Ativa}

LOPES, Teresa Rita. Pessoa por conhecer: Textos para um novo mapa. Lisboa: Editorial Estampa, v. II, 1990.

PESSOA, Fernando. Correspondência Inédita. Organização de Manuela Parreira da Silva. Lisboa: Livros Horizonte, 1996.

Obras de Fernando Pessoa. Introduções, organização, biobibliografia e notas de António Quadros. v. I. Porto: Lello \& Irmão, 1986a. 
. Obras de Fernando Pessoa. Introduções, organização, biobibliografia e notas de António Quadros. v.II. Porto: Lello \& Irmão Editores, p. 1986 b.

. Obras de Fernando Pessoa. Introduções, organização, biobibliografia e notas de António Quadros. v.II. Porto: Lello \& Irmão Editores, p. 1986c.

Páginas Íntimas e de Auto-Interpretação. Textos estabelecidos e prefaciados por G.

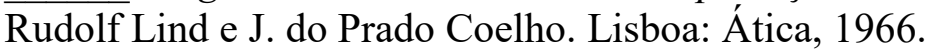

Pessoa Inédito. Coordenação de Teresa Rita Lopes. Lisboa: Livros Horizonte, 1993.

\section{Passiva}

BATE, Jonathan. The genius on Shakespeare. London: Macmillan, 1997.

BRÉCHON, Robert. Fernando Pessoa: l'échec \& la gloire. In: Estudos Portugueses. Homenagem a Luciana Stegagno Picchio. Lisboa: Difel, 1991, p. 681-690.

CASTRO, Mariana Gray de. A autobiografia shakespeariana de Fernando Pessoa. In: PETROV, Petar et al. Avanços em Literatura e Cultura Portuguesas: de Eça de Queirós a Fernando Pessoa. Faro: Através, 2012, p. 321-336.

COELHO, Jacinto do Prado. Fernando Pessoa, pensador múltiplo. In: PESSOA, Fernando. Páginas intimas e de auto-interpretação.Textos estabelecidos e prefaciados por Georg Rudolf Lind e J. do Prado Coelho. Lisboa: Ática, 1966, p. XXI-XXXVII.

CRESPO, Ángel. Estudos sobre Fernando Pessoa. Lisboa: Teorema, 1988.

ESTIBEIRA, Maria do Céu Lucas. A Marginalia de Fernando Pessoa. 2008. Tese (Doutorado em Literatura Comparada) - Faculdade de Letras, Universidade de Lisboa, Lisboa, 2008.

FINAZZI-AGRÒ, Ettore. O alibi infinito - O projecto e a prática na poesia de Pessoa. Lisboa: Imprensa Nacional-Casa da Moeda, 1987.

FLOR, João Almeida. Fernando Pessoa e a Questão Shakespeariana. In: Afecto às letras. Homenagem da Literatura Portuguesa Contemporânea a Jacinto do Prado Coelho. Lisboa: Imprensa Nacional-Casa da Moeda, 1987, p. 276-283.

GIL, José. Metafísica e heteronímia na obra de Fernando Pessoa. Encontro Internacional do Centenário de Fernando Pessoa. Lisboa: Fundação Calouste Gulbenkian, 1990, p. 128-130.

IRIMIA, Mihaela. In Search of "what's in a name": The English Pessoa as Poet as SHAKESPEARE, and the Case of SuperCamões. A Journal of Literary Studies and Linguistics, v.1, n. 1, p.73-83, 2001.

LIND, Georg Rudolf. Estudos sobre Fernando Pessoa. Lisboa: Imprensa Nacional-Casa da Moeda, 1981.

LOPES, Maria Teresa Rita. Fernando Pessoa et le drame symboliste: héritage et création. Paris: Centre Culturel Portugais, 1977. 
LOURENÇO, Eduardo. Fernando, Rei da nossa Baviera. Lisboa: Imprensa Nacional-Casa da Moeda, 1986.

MONTEIRO, Maria da Encarnação. Incidências inglesas na poesia de Fernando Pessoa. Biblos, v. XXXI, p. 21-123, 1955.

MONTEIRO, Taïs Campos. Mais além do drama poético de Fernando Pessoa. Lisboa: Imprensa Nacional-Casa da Moeda, 2006.

NUTTIN, J. A estrutura da personalidade. Rio de Janeiro: Zahar, 1982.

PAZ, Octávio. O desconhecido de si mesmo, Iniciativas Editoriais, s/d.

PICCHIO, Luciana Stegagno. Clés de lecture. In: AA. VV. Fernando Pessoa - Poète pluries. Paris: Centre Georges Pompidou et Éditions de la Différence, 1985, p. 29-34.

QUADROS, António. O Primeiro Modernismo Português - Vanguarda e Tradição. Lisboa: Publicações Europa-América, 1989.

RUSSO, Vincenzo. Fernando Pessoa: a peripheral Shakespearean out of his time. In: CIANCI, Giovanni (Org). Will the Modernist: Shakespeare and the Historical European Avant-Gardes. Oxford: Peter Lang, 2014, p.191-205.

SENA, Jorge de. O heterónimo Fernando Pessoa e os poemas ingleses que publicou. In: PESSOA, Fernando. Poemas Ingleses. 4. ed. Lisboa: Ática, 1994, p. 11-87.

SEVERINO, Alexandre E. Fernando Pessoa e William Shakespeare: um estudo comparativo de Heteronímia. In: ACTAS DO IV CONGRESSO INTERNACIONAL DE ESTUDOS PESSOANOS, 1., 1990, Porto. Anais... Porto: Fundação Eng. António de Almeida, 1990, p.13-22.

SOUZA, Cláudia Franco Souza. Fernando Pessoa And English Literature. Revista da Anpoll, n. 36, Florianópolis, n. 36, p. 312-329, jan./jun. 2014.

CRESPO, Antonio. Pessoana mínima. Lisboa: Imprensa Nacional-Casa da Moeda, 1984.

VILA MAIOR, Dionísio. Fernando Pessoa: Heteronímia e Dialogismo. Coimbra: Livraria Almedina, 1994.

Fernando Pessoa: uma discursividade polifónica. Convergência Lusíada, Rio de Janeiro, n. 12, p. 127-155, 1995.

Bakhtinian Dialogism and the Adding of Meaning. In: MARQUES, Lénia, BISCAIA, Maria Sofia Pimental, BASTOS, Glória (Ed.). Intercultural Crossings. Confilt, Memory and Identity. Bruxelles: Peter Lang International Academic Publishers, p.189-204, 2012.

Fernando Pessoa and the Shakespeare's "voice"

Abstract: I will try to reflect on the sense of "emulation" that is perceptible in some texts of Fernando Pessoa, in what concerns the relations with some other canonical writers; I will discuss the relationship that Pessoa maintained with Shakespeare, as well as the dialogical 
relationship that is possible to deduce in the procedures of creation of Pessoa's heteronyms and in the creation of Shakespearean characters. From this perspective, I will try to focus on several issues: in the "Shakespearean problem" (recalling some examples capable of clarifying a specific position of the Portuguese poet towards Shakespeare); In terms of "alterity" - as well as in the conception of Pessoa as "dramatic poet", of the "degrees of poetry" and of the "dialogical dynamics" of Fernando Pessoa's heteronymy (which immediately returns us to the theory of "Artistic lie"); In the problem of the "psychological figuration" of the poet of the heteronymic personages, as well as of the poet born in Stratfordupon-Avon; In the "anxiety of influence" (through which we will study the role of the heteronym Alberto Caeiro).

Keywords: Fernando Pessoa. Shakespeare. Dialogical dynamics. Heteronyms. Characters.

Recebido: $13 / 02 / 2017$

Aceito: $13 / 03 / 2017$ 